\title{
Integrating the supply chain management system operated by multinational corporations within global logistics
}

\author{
Peter J. Rimmer ${ }^{*}$ and Mary Krome Hamilton ${ }^{* *}$
}

\begin{abstract}
Intersectionist, unionist and relabelling models have largely superseded the subsumption of supply chain management within logistics that formed the basis of the traditionalist model. As there is little congruence between logistics and supply chain management in the emergent intersectionist model, this is eliminated from consideration at the outset. However, an examination of the new unionist and relabelling models, offering differing permutations of the relationship between logistics and supply chain management, suggests that they offer a misleading foundation for examining the costs involved with the dispersal of supply chain activities across the world. The root problem is the failure to integrate the industrial goods transformation network operated by multinational corporations with the global transport and communications network. Reverting to privileging the global transportation and communications network over the industrial goods transformation network in a revamped traditionalist model can overcome this difficulty and open up new research vistas.
\end{abstract}

Keywords: global transportation and communications network, industrial goods transformation network, logistics, multinational corporations, supply chain management.

\section{Introduction}

The key to successful supply chain management (SCM) by multinational corporations hinges

Submission date: 18/02/2008_Revision date: 29/05/2008_Acceptance date: 10/06/2008

${ }^{*}$ Corresponding author, Professor, Division of Pacific and Asian History, Research School of Pacific Studies, ANU College of Asia and the Pacific, The Australian National University, Canberra, ACT 0200, Australia. E-mail peter.rimmer@anu.edu.au

${ }^{* *}$ Professor, College of Business Administration, University of Rhode Island, 309 Ballentine, 7 Lippit Road, Kingston, Rhode Island, USA 02818. E-mail marykrome@gmail.com 
on integrating the network transforming industrial goods with the global transportation and communications network. Studying this phenomenon has proved elusive because the two networks have been studied as separate entities with few cross-linkages.

The dominant analytical trend in logistics and supply chain management identified by Frédéric Masbonçon (2005) has been to abandon the 'traditionalist model' in which supply chain management is subsumed in logistics and to pursue one of three variants identified by Larson and Haldorsson $(2002,2004)$. As depicted in Figure 1 these variants, derived from surveying experts in logistics and supply chain management in the United States, are generated either by:

(i) retaining logistics and supply chain management as overlapping separate entities in an 'intersectionist model';

(ii) subsuming logistics into supply chain management in an 'unionist model'; and

(iii) redesignating logistics as supply chain management in a 'relabelling model'.

Other ways of distinguishing between logistics and supply chain management are available in the literature (e.g. Christopher, 1998), but these three representations should suffice for our discussion, which is designed as an alternative framework for further exploration and research.

(a) Traditionalist Perspective

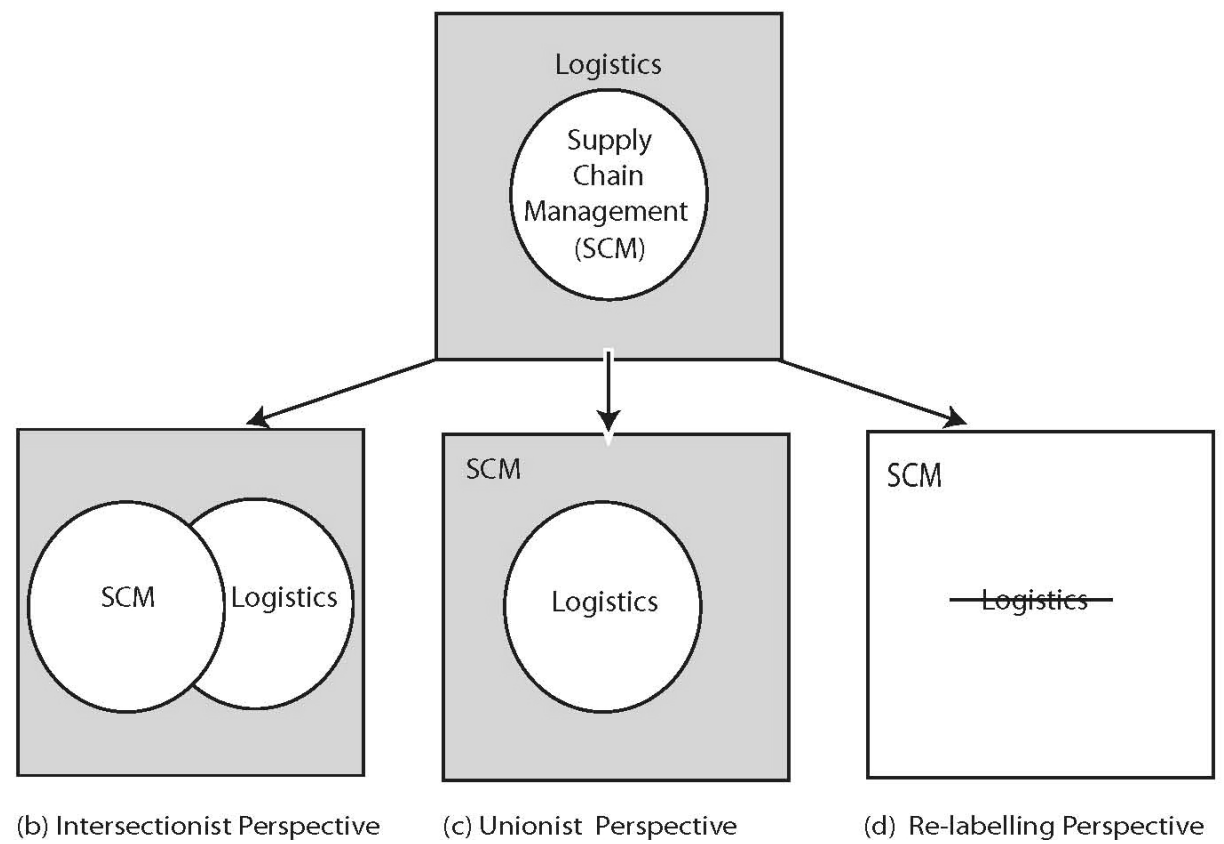

Source: Adapted from Larson and Haldorsson, 2004: 19; and Masbonçon, 2005

Figure 1. Four different permutations of the relationship are shown between logistics and supply chain management 
Implementing the intersectionist model requires considerable care: logistics issues such as internal transport that do not involve inter-organizational relations are only considered in the logistics field; supply chain management issues such as marketing matters and financial issues are not covered in logistics; and the overlapping congruence between logistics and supply chain management is restricted to inter-organizational logistics collaboration. As the intersectionist model is still emerging as an analytical framework (see Sandberg, 2005), it is not pursued further in this study and attention centred upon the unionist and relabelling models.

The unionist and relabelling models turn out to be different from what they claim when we seek to comprehend the costs associated with dispersing supply chain activities across the globe. In effect, these two variants of the traditionalist model lead to a misunderstanding of how international supply chains should be managed by multinational corporations (i.e. at the industry level).

This misunderstanding raises a series of issues. Why are the alternative models different from what they claim? How can we resolve this matter? More specifically, what are the implications of reversing the dominant analytical trends in studying international supply chain management and returning, albeit in a revitalized form, to the traditionalist model?

Initially, in addressing these issues we outline the fundamental shortcomings of the unionist and relabelling models in international supply chain management by highlighting their failure to accommodate the intersection between the multinational production system and the global transportation and communications network. Then we demonstrate how their shortcomings can be overcome by prioritising the global transportation and communications network over the multinational supply chain system. This strategy involves the re-adoption of the overtly traditionalist model that subsumes supply management into logistics (see Fig. 1).

\section{Shortcomings of the unionist model}

The prime focus at the firm level has been on goods transformation rather than global transportation and communications. Invariably, the Chief Executive Officers (CEOs) of Multinational Corporations (MNCs) with headquarters spread around the world indicate that international supply chain management is a priority. However, a survey by Charan and Colvin (1999) suggests that some 70 per cent of them say that they have not been able to evaluate their supply chain's performance. We argue that the reason their performance cannot be evaluated is that they are using an analytical framework with narrow global logistics concepts.

This leads to the preoccupation of MNCs with firm level systems such as inventory management. As reported by Bain \& Company (2002) and Sheppard and Kent (2002), surveys showed that three-fifths of all managers consider inventory management as the most important attribute. Firm level concentration on transportation and information management emphasizes the traffic flows inherent in inbound and outbound logistics. Transport costs and shipment issues are transferred to the customer at the next stage of the supply chain along with ownership of the inventory. In the case of Wal-Mart, control at the firm level can be established by exercising power over the individual components (Olmsted-Teisberg, Freeman and Mead, 2003; Freeman and Mead, 
2006; Brunn, 2006). This preoccupation leads to the fundamental assumption that individual firms can manipulate supply chain activities through vertical integration and supply chain control to create a competitive advantage (Porter, 1985).

The firm focus makes it difficult to integrate the industrial goods transformation systems of multiple firms with the global transportation and communications network. Fundamentally, this irreconcilability stems from a clash in the rules of engagement involving transactions between the two networks. One is intrinsically competitive and the other, by its very nature, seeks to be cooperative. As long as we subsume logistics under supply chain management what we have is behavior dictated solely by the rules of competition that favor the strongest individual firm on the supply chain rather than integrating rules that also favor cooperation. There is no attempt at developing a hybrid behavioral pattern that Brandenberger and Nalebuff (1996) have referred to as 'co-opetition'.

\section{Shortcomings of the relabelling model}

Switching the focus to relabelling is designed to broaden logistics so that it covers all goods transformation activities along the supply chain. At the supply chain level this perspective, as typified by the computer company Dell Inc., keeps individual firms focused on their core competencies and on cooperation between supply chain partners in transforming natural resources into consumer goods. The interests of a group of individual firms within a consortium center upon horizontally integrated inter-group linkages so that individual firm efficiencies can be attained while still meeting overall market requirements. The focus on transportation and information management, however, is still at the firm level. Without this emphasis at the group level, efficiencies in transfer activities cannot be attained. Adoption of a group strategy would move logistics beyond considerations of inbound and outbound flows within an individual firm to all the linkages along the supply chain.

In the Dell case the linkages within a consortium are 'pooled' around one central assembler and distributor; each component in this cooperative arrangement, including the central assembler and distributor, are joined by the necessity of contributing one component to the final product (Magretta, 1998; Kraemer and Dedrick, 2000; Kapuscinski, et al., 2004). This enables the consortium to address individual customer needs.

The problem with the Dell case is that the system is closed and no consideration is given to the efficiencies that may be attained through transportation management. Essentially, we are still dealing with a closed system as little consideration is given to any logistics issues outside their respective domains. 


\section{A revamped traditionalist model}

Without looking at the global transportation and communications network it would not be possible to have seamless connections between geographically dispersed supply chain activities. This network is a group of both related and unrelated firms across industries that propel the movements of goods around the world. Conversely, individual firms create value for themselves in the other analytical framework. In this instance the global transportation and communications network is essential for the operation of individual firms. Therefore, the network itself creates value for the firms (e.g. airlines and telecommunications).

If you look at supply chain management encompassed within global logistics, attention shifts from firm level attributes to the architecture of the global transportation and communications network. As evident in switching from pull to push supply chain systems, the priority changes from inventory management to an emphasis on accessibility and utilization of transportation and communications services (Table 1). In particular, interest is centered upon network promotion and contract management, service provisioning and infrastructure operations (Stabell and Fjeldstab, 1998). In the process we have moved from inter-linked chains to layered and denser networks that cross industries. In this arrangement the system is opened up not only to related firms in a cooperative grouping (e.g. Dell) but also to unrelated firms.

Table 1

Change in relative importance of transportation and communications, information and inventory in switching from push to pull supply chain systems

\begin{tabular}{c|c|c|c}
\hline \multirow{2}{*}{ System } & $\begin{array}{c}\text { Transportation\& } \\
\text { communications }\end{array}$ & Information & Inventory \\
\cline { 2 - 4 } & percent & percent & percent \\
\hline \hline Push & 20 & 10 & 70 \\
Pull & 35 & 50 & 15 \\
\hline
\end{tabular}

Source: Derived from Figures 34a and 34b in AASHTO (2002:49).

What becomes important is the network itself, which interconnects the movement of goods and services across the globe. Moving from the industry or consortium level to a cross-industry level results in subsuming supply chain management under a broader global logistics framework.

\section{The way ahead}

Supply chain management is a smaller proportion of global logistics. It becomes important for 
multinational corporations examining logistics to consider network attributes in supply chain management. In consequence, business logistics cannot concentrate solely on inbound and outbound flows; it has also to incorporate network connections. Thus, any consideration of logistics has to be as broad as the transportation and communications network within which the industry or consortium operates. In other words, the firm's purview has to be global.

Inevitably, this raises the issue of how to deal with the complexity within the coterminous multinational supply chain and global transportation and communications network. All we can do at a conceptual level is to indicate how the global transport and communications network (sea-land, air and telecommunications) is enmeshed with a series of multinational supply chains across industries (Fig. 2).

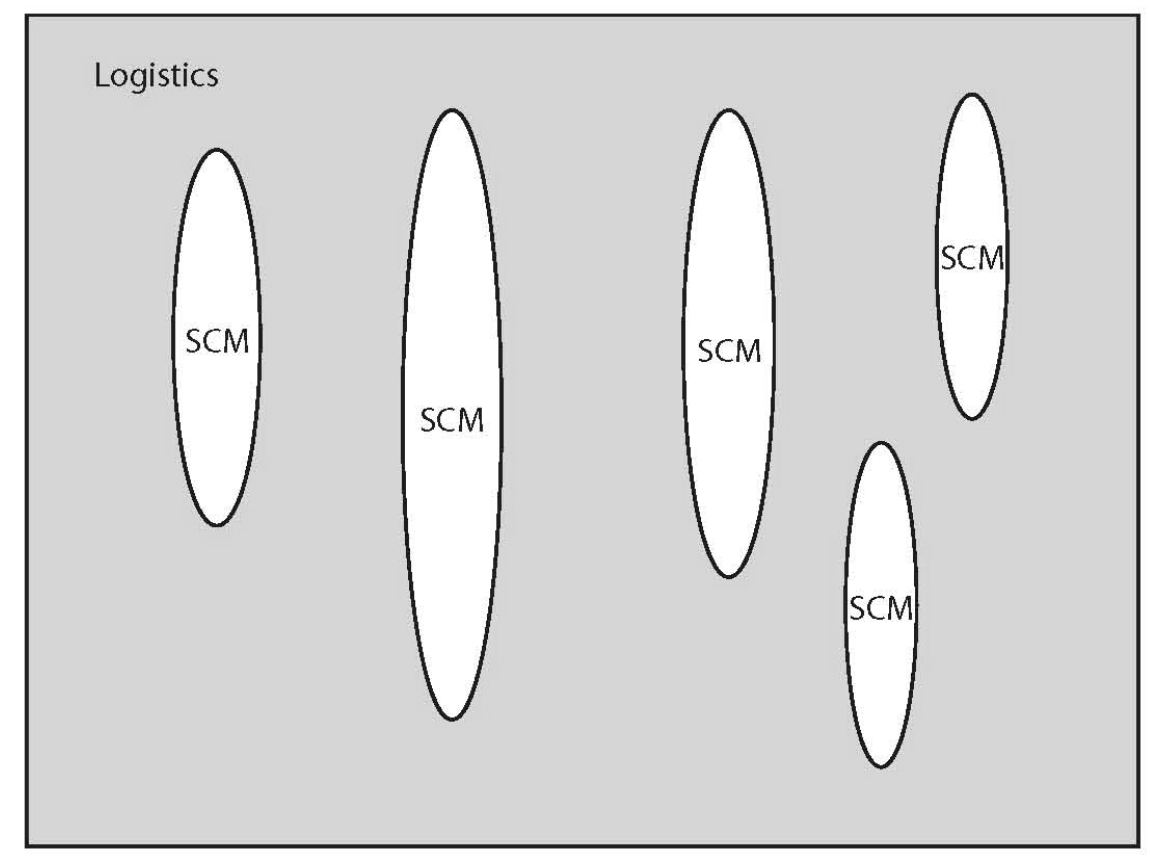

Figure 2. The global logistics network in which supply chains are embedded.

The implications of our approach require the abandonment of the trend towards the unionist perspective, which subsumes logistics into supply chain management within a closed system. Also our approach does not entertain relabelling logistics as 'supply chain management' to accommodate a bigger arena of corporate interest.

Rather than resorting to an 'intersectionist' approach, which we abandoned at the outset because it examines two systems with little overlapping congruence, we return to the so-called traditionalist model in which supply chain management is subsumed under a global logistics 
framework.

At the multinational level you have the simple traditionalist model. However, at the transportation network level there are a series of supply chains across industries within the global logistics framework. This suggests that they are not completely parallel systems.

Instead the supply chains are nested within a broader global logistics framework (Fig. 2). The difference between the two lies in how they are evaluated. At the multinational level supply chain management still takes priority but also must incorporate the network attributes that affect the cost structure, timing of the shipments, conditions of consignments as the goods move through the supply chain. Thus the transportation infrastructure is of paramount importance to supply chain management.

In the transportation network the focal point is on global logistics with a secondary emphasis on accommodating numerous supply chains that cross industries. Therefore, from either side, it is important to look at both global logistics and supply chain management.

\section{Conclusions}

This study has presented a conceptual framework to examine supply chain management within a global transport network. The focus has involved disregarding the emergent 'intersectionist' model at the outset.

Also we have demonstrated that the other dominant trends in studying supply chain management - the unionist and relabelling models — are inadequate and that we need to return to a traditionalist model. In moving back we have recast the model to accommodate both the management of multinational supply chains and the larger global transportation and communications network under a single umbrella.

In returning home to the traditionalist network approach we have gone beyond the original framework to develop a new nested model in which the larger transport network is able to accommodate almost innumerable supply chains. Clearly, we are not dealing with a homogenous process.

This broader framework, incorporating both location and linkages, enables component specializations to focus on activities that are industry and service specific (e.g. supply chains and transport companies involved in sea-land and air operations). This specialization improves the quality of the network and enhances the autonomy of the individual components without ceding controlling power to any dominant member (i.e. the overarching umbrella itself is not under the control of any dominant member). It is the parties involved and the alliances that are developed which make the network effective or ineffective. This enables complex phenomena like global logistics to be comprehended at either the firm level or at the network level. 


\section{Acknowledgements}

Our paper was stimulated in response to one by Frédéric Masbonçon of the Centre d'etude et de recherche en economie et gestion logistique (CERENE) Laboratory, Institut supérieur d'etudes logistiques (ISEL), University of Le Havre, France. His paper on "Reality, Opportunities and Risks of Supply Chain Management Projects" was delivered at an international seminar entitled 'Three Invited Lectures on Global Logistics \& Supply Chain Management" held at Inha University, Incheon, South Korea in 2005 and sponsored by the Jungseok Research Institute of Trade and Logistics(JRI). Two reviewers are thanked for their comments.

\section{References}

AASHTO. 2002. Transportation: Invest in America - Freight Rail Bottom Line Report, Washington, D.C.: American Association of State Highways and Transportation Officials, http://www.freight.transportation.org/doc/FreightRailReport.pdf (accessed 4 June 2007).

Bain \& Company. 2002. Why Companies Flunk Supply-Chain, Business Library, http://jobfunctions.bnet.com/whitepaper.aspx?docid=59194.

Brandenburger, A. M. and B. J. Nalebuff. 1996. Co-Opetition: A Revolution Mindset That Combines Competition and Cooperation: The Game Theory Strategy That's Changing the Game of Business. New York, Doubleday.

Brunn, S.D. 2006. Wal-Mart World: The World's Biggest Corporation in the Global Economy. New York: Routledge.

Charan. R. and G. Colvin. 1999. Why CEO's fail. Fortune Magazine. 138(12).

Christopher, M. 1998. Logistics and Supply Chain Management. $2^{\text {nd }}$ ed., London: Pitman.

Freeman, R.E. and J. Mead. 2006. Wal-Mart in 2005 (A). Darden Business Publishing, Ref: UVAE-0282, http://store.darden.virginia.ed (accessed 4 June 2007).

Kapuscinski, R., R.Q. Zhang, P. Carbonneau and R.M.B. Reeves. 2004. Inventory decisions in Dell's supply chain. Interfaces. 34(3): 191-205.

Kraemer, K.L. and J. Dedrick. 2002. Dell Computer: organization of a global production network. Center for Research on Information Technology and Organizations, Globalization of IT, Paper 255, Irvine: University of California, http://repositories.cdlib.org/crito/ globalization/255 (accessed 5 May 2007).

Larson, P.D. and A. Haldorsson. 2002. What is SCM and where is it? Journal of Supply Chain Management. 38(4): 36-44.

Larson, P.D. and A. Haldorsson. 2004. Logistics versus supply chain management: an international survey. International Journal of Logistics: Research and Applications. 7(1): 17-31.

Magretta, J. 1998. The power of virtual integration: an interview with Dell Computer's Michael 
Dell. HBR Online, Harvard Business Review. March-April: 72-84, http:/harvardbusinessonline.hbsp.harvard.edu/hbsp/hbr/articles/article.jsp?articleID=9 8208\&ml_action=get-article\&print=true (accessed 19 May 2007).

Masbonçon, Frédéric. 2005 . Reality, opportunities and risks of supply chain management projects. unpublished presentation at Jungseok Research Institute (JRI) International Seminar entitled "Three Invited Lectures on Global Logistics \& Supply Chain Management", International Convention Center, Jungseok Memorial Library, Inha University, Korea, 18 May 2005.

Olmsted-Teisberg, E., R. E. Freeman, and J. Mead. 2003. Wal-Mart in the 21st century: a global perspective. Darden Business Publishing, Darden Case No. UVA-S-0100-SSRN, http://ssm.com/abstract=508722 (accessed 4 June 2007).

Porter, M. E. 1985. Competitive Advantage: Creating and Sustaining Superior Performance. New York: The Free Press.

Sandberg, E. 2005. Logistics Collaboration in Supply Chains: A Survey of Swedish Manufacturing Companies. Dissertations from the Graduate School of Management and Industrial Engineering IMIE No 93 Licentiate Thesis and Linköping Studies in Science and Technology Thesis No. 1180 (LiU-TEK-LIC 2005-35), Linköping: Logistics Management, Department of Management and Economics, Institute of Technology, Linköping University, www.diva-portal.org/diva/getDocument?urn_nbn_se_liu_diva498-1_fulltext.pdf(accessed 19 May 2007).

Sheppard, I. and D. Kent. 2002. Executive interviews reveal weak spots in supply chain management. Semiconductor Fabtech, 16: 37-40 cited by B. Tomlin. On the value of mitigation and contingency strategies for managing supply chain disruption risks. Management Science. 52 (5), 2006: 639-657.

Stabell, C.B. and Ø.D. Fjeldstad. 1998. Configuring value for competitive advantage: on chains, shops, and networks. Strategic Management Journal. 19 (5): 413-437. 